\title{
Study on the Development Path of Cultural and Creative Products in the Changzhou Section of the Grand Canal
}

\author{
Musheng Yang ${ }^{1, *}$ \\ ${ }^{1}$ College of Art and Design, Jiangsu University of Technology, Changzhou, Jiangsu 213001, China \\ *Corresponding author. Email: jsyangmusheng@163.com
}

\begin{abstract}
Cultural and creative products have strong cultural, artistic and regional characteristics, and are important carriers for the communication of the Grand Canal culture. Changzhou section of the Grand Canal, as one of the oldest river sections in China, has formed a rich and colorful cultural scene along the river through the development of previous dynasties. However, most of the existing canal cultural and creative products in Changzhou are simply copied, labelled and sold, lacking the cultural characteristics and cultural connotation of Changzhou canal. The development of cultural and creative products should focus on Changzhou's representative canal cultural symbols at the material and spiritual levels, the product design and story content, and the improvement of communication power.
\end{abstract}

Keywords: Changzhou canal culture, Cultural and creative products, Development path.

\section{INTRODUCTION}

In June 2017, General Secretary Xi Jinping stated in the article "Creating a golden card to showcase Chinese civilisation - Some thoughts on the Grand Canal Cultural Belt" in Issue 48 of "Research Highlights" issued by the Central Research Office, "the Grand Canal is a valuable heritage left to people by ancestors, and also a mobile culture. It is necessary to protect it, pass it on and make good use of it". As a province rich in canal cultural resources, Jiangsu Province clearly puts forward the design of "three corridors" to strengthen cultural protection and industrial development. Changzhou is also actively engaged in the protection, inheritance and innovation of the Grand Canal culture. The municipal government has issued relevant documents and implemented them well. For example, in recent years, the

*Funds: General Project of Philosophy and Social Science Research of Jiangsu Colleges and Universities — "Research on the Design and Communication of Jiangsu Grand Canal Cultural and Creative Products Driven by Cultural Resources" (2019SJA1075); 2021 Jiangsu Provincial Excellent Project of Applied Research in Social Sciences — "Research on Rural Cultural and Creative Industries Development and Brand Communication from the Perspective of Rural Revitalization: Taking Changzhou as the Example" (21SYA-023).
Qingguo Lane reconstruction project along the Changzhou section of Grand Canal, the protection of the Ming Dynasty City Wall, the cultural and creative festival of Grand Canal and so on all reflect Changzhou's attention to the cultural protection, inheritance and innovation of the Grand Canal. "Culture" is the root of the Grand Canal. To effectively protect the Grand Canal, it is required not only to simply protect historical sites, but also carry forward the "Grand Canal Culture" in combination with the background of the times. Designing and developing cultural and creative products is a positive and effective method, because it is easier for people to remember intuitive products. Changzhou section of the Grand Canal is rich in cultural resources, but the design and development of cultural and creative products has not received due attention and is still in the initial stage of exploration. From the current development situation, the promotion of canal culture, the protection of intangible cultural relics of the canal and the excavation and shaping of tourism cultural display of canal sites are carried out mainly along the canal, but there are few cultural and creative brands or products with high popularity and reputation. Most of the existing canal cultural and 
creative products in Changzhou are simply imitated, copied and labelled for sale, lacking the cultural characteristics and cultural connotation of Changzhou section and being difficult to spread.

Combining the development of cultural and creative products with the cultural inheritance and activation of the "Changzhou section of the Grand Canal" is of strong application value and practical significance. First of all, it is suggested to combine the Changzhou canal culture with the creative design of products, and design the cultural and creative products of the Grand Canal with Changzhou cultural characteristics, which can be transformed and popularized, and has strong market development value. At the same time, it also helps to clarify the design and development ideas of cultural and creative products of Changzhou Grand Canal and enrich relevant research results. Secondly, it helps to activate, inherit and carry forward the Grand Canal Culture with Changzhou characteristics.

\section{DEVELOPMENT STATUS OF CULTURAL AND CREATIVE PRODUCTS IN CHANGZHOU SECTION OF THE GRAND CANAL}

\subsection{Lacking Perfect Cultural and Creative Product Development System of Changzhou Section of Grand Canal}

At present, the cultural and creative products of Changzhou Grand Canal have not formed an effective development system, resulting in that there is no independent brand of cultural and creative products of Changzhou Grand Canal. At present, cultural and creative products on Changzhou Grand Canal culture can be seen in cultural and creative stores of Changzhou Museum, Changzhou Comb Factory, specialty stores, etc. Firstly, Changzhou currently lacks talents in the development and management of cultural and creative products of the Grand Canal. Changzhou municipal government vigorously supports the development of cultural and creative industries, but there are few targeted teams for the research and development. Nanjing Museum, located in the ancient capital of Nanjing, has actively introduced a batch of talents in the development, design and management of cultural and creative products by virtue of its geographical advantages, has carried out targeted subdivision and mining of Nanjing's cultural characteristics, including the excavation of canal culture, has formed a series of cultural and creative products, and has carried out online and offline communication, so as to obtain good benefits and spread the characteristic culture of Nanjing. Secondly, the existing cultural and creative products in Changzhou do not show the main canal cultural characteristics, and Changzhou develops cultural and creative products based on Changzhou Museum. At present, there are few categories of cultural and creative products of Changzhou Museum. The existing intangible cultural relics such as comb, embroider and other products are mainly designed in the form of personal studio and limited company. The cultural characteristics of Changzhou Canal are not highlighted in product development and communication.

\subsection{Lacking Creativity and Cultural Connotation}

The imitation and reproduction of cultural and creative products of Changzhou Grand Canal is serious, lacking personalized creativity and cultural connotation, and being unable to express the cultural characteristics of Changzhou section of the Grand Canal and difficult to produce spiritual consumption at the level of cultural identity. It is observed that most of the cultural and creative products of the Grand Canal that have been produced and sold cannot deeply explore the cultural elements of the Changzhou Canal or refine the unique cultural symbols of the Changzhou Canal, but stay at the level of image design of some tourist souvenirs. In addition, the product modelling design and pattern design tend to use old popular traditional elements, becoming a mere formality and lacking the innovation. For example, a bamboo carving product sold in Changzhou Museum Store, named "appreciating autumn scenes in the form of bamboo carving", inherits the bamboo carving technology of leaving the green with Changzhou characteristics, but the product content and pattern are not innovated. Most of the product materials are traditional bamboo, and the price is generally high, so it is difficult to attract mass consumers, especially young consumers. In terms of product development, it is required to pay attention to mass consumption habits. Alternative materials can be appropriately selected, and new products can be developed for mass consumers in terms of practicability and commemoration, such as key chains, bookmarks, stationery based on the theme of bamboo carving of leaving green. 


\subsection{Weak Awareness of Property Rights Protection}

With the wide and rapid spread of We-Media and the upgrading of cultural and tourism consumption, cultural and creative products are easy to be imitated. When a cultural and creative product is hot, there will be different degrees of imitation and plagiarism in the market. At present, China has many laws and regulations to protect intellectual property rights, such as "Patent Law", "Copyright Law" and so on. However, rights protection requires a lot of time and money. In addition, most enterprises engaged in the research and development and design of cultural and creative products are small and medium-sized enterprises or small and micro enterprises or even individuals. The maintenance energy and capital of intellectual property rights are limited, which affects the effective transformation of the cultural value of innovative products. Through the field visit to the Changzhou Grand Canal, it is found that Changzhou combs are basically homogeneous. There are two comb stores in the South Street in the center of Changzhou, one is based on the old comb factory in Changzhou, and the other is a comb brand established by itself, but they are basically similar in brand publicity and have no characteristics. There are also Changzhou specialty stores selling all kinds of Changzhou specialties in the underground shopping malls and Biji Lane in the city center, such as Changzhou comb, whose packaging is the same. Besides, the products are of poor quality and chaotic, and consumers can't distinguish the authenticity.

\section{DEVELOPMENT STRATEGY OF CULTURAL AND CREATIVE PRODUCTS OF CHANGZHOU CANAL}

\subsection{Symbolic Transformation of Changzhou Canal Culture}

The value or meaning conveyed by symbols is endowed by the unique cultural sum of social groups. Therefore, cultural symbols are the figurative forms of spiritual expression at the inner level of human beings. They are symbolic symbols used to convey identity information and distinguish other objects. "Culture includes a set of tools and a set of customs - human or spiritual habits, which directly or indirectly meet human needs." [1] When a social group meets cultural symbols that meet their spiritual demands, they will be keen to pursue this external marker to flaunt their identity, status and personality. Cultural and creative products are commodities with certain cultural attributes. For consumers, they are a kind of symbolic consumption or symbolic consumption. Consumers not only consume the function of the product, but also experience the personality contained in the product. If the designers want to design Changzhou Grand Canal cultural and creative products that meet the emotional demands of consumers, it is necessary to carry out a reasonable symbolic transformation of abstract Grand Canal culture to form concrete cultural symbols, so as to win the recognition of consumers.

From the material and cultural level, the landscape relics along Changzhou Grand Canal can be creatively reproduced as canal memory symbols. First, the landscape reproduction of the remains of Changzhou canal and water conservancy project mainly includes all canal sections in Changzhou (navigation part and forbidden part of Changzhou west section of old canal under key protection, navigation part and forbidden part of Changzhou east section of the old canal, city section of old canal, Nanshi River and Dongshi River), ancient bridges on the canal (suo bridge, Zhongxin bridge, Xinfang bridge, Caihong bridge, Baoshan bridge, etc.), wharf relics (Royal wharf, grand wharf, Shangshu wharf, etc.) and various gates, weirs, dams, etc. [2]. Second, towns along the canal and related cultural relics mainly include ancient city walls (such as Weidun Neolithic site, Yancheng site, lanling site, etc.), towns bred by canals (Benniu Town, Menghe Town, Wei Village, Qishuyan District, etc.), ancient buildings and sites along the coast (Architectural Complex of the Republic of China in Damingchang, Architectural Complex of the Republic of China in Qijichang, Tang Jingchuan's house, Tianning Temple, Writing Brush Pagoda, Dongpo inkstone washing pond, Sheng Xuanhuai's former residence, Daotai mansion, Hengyuanchang office building, etc.), historical blocks (Biji lane, Yangqiao Historical and Cultural Street, Yizhou Pavilion - Hongmeige historical and cultural block, Qingguo Lane, etc.). The ancient scenery of these canals can be reproduced by hand painting, traditional Chinese painting, disordered needlework, bamboo carving of leaving green and other forms, and corresponding cultural and creative products can be formed. 


\subsection{Story Refining of Changzhou Canal Culture}

In terms of communication, story, as an ancient narrative symbolic text, is a way for people to convey emotion and cultural charm. C. Bremond, a French structuralist narrator, once said: "the theme of a story can be used as the plot of a ballet; the theme of a novel can be applied to the stage or screen; a film can be told to people who have not seen it. What people read is text. What people see is the image, and what people recognize is the posture. Through these, people would learn a story, and it may be the same story." [3] It can be seen that story is not only a literary language, but also permeates various disciplines and plays a role of symbol communication.

Escalas J. E believes that stories can attract consumers, fascinate consumers and entertain consumers. More importantly, the story can communicate, persuade, prove and show the products that how should be used and how to use them." [4] If people can extract a series of stories or allusions from Changzhou Grand Canal Culture and apply them to the creation of product content, it will reduce the communication cost of products to a certain extent and increase consumers' desire to buy. "Once the symbol is endowed with meaning by people, and will enter the communication system of information after universal recognition and agreement." [5] Applying the narrative method of story to the content creation of products can add value to the cultural power of cultural and creative products of Changzhou Grand Canal, and form a series of product stories deeply rooted in the hearts of the people, which are easier to be accepted and recognized by consumers. "Situational story method is used to design cultural products with connotation and contributes to product cultural innovation" [6]. From the perspective of spiritual culture, literati and craftsmen of previous dynasties bred in Changzhou canal left rich and colorful poems, paintings and intangible cultural relics, such as handicrafts that have been handed down for a long time (disordered needlework, bamboo carving of leaving green, comb, etc.), myths and folklores (Legends of Qianlong and $\mathrm{Su}$ Dongpo in Changzhou, legends of Dong Yong, etc.), folk activities (Furong Danghu, "shangsan" market, Hengshanqiao fair, Spring Festival, etc.), poets and poems (such as Liu Yuxi in the Tang Dynasty, Su Shi in the Song Dynasty and their poems). These abstract cultural symbols are reproduced on cultural and creative products through artistic techniques, graphics, videos and other forms to form spiritual symbols unique to Changzhou canal culture, and tell beautiful stories about Changzhou section of Grand Canal in the form of "story telling" loved by the audience.

\section{CONCLUSION}

It is found that the cultural and creative products of Changzhou Canal must be rooted in the unique cultural resources of Changzhou section of the Grand Canal and better reflect its representative cultural symbols, such as material cultural symbols and spiritual cultural symbols. In terms of product development, the cultural symbols with the characteristics of Changzhou canal are refined and injected into the product design to increase the uniqueness of the product; from the perspective of communication, it is required to create story content according to the spiritual culture of Changzhou canal, increase the communication power of products, and make Changzhou canal cultural and creative products more cultural and aesthetic. Finally, the cultural essence of Changzhou section of the Grand Canal can obtain emotional identity among the general public, and a canal cultural and creative brand with Changzhou's own characteristics and a good social image would be formed.

\section{AUTHORS' CONTRIBUTIONS}

This paper is independently completed by Musheng Yang.

\section{REFERENCES}

[1] [Poland] Bronislaw Malinowski. The Theory of Culture [M]. Translated by Fei Xiaotong. Beijing: The Commercial Press, 1946: 10. (in Chinese)

[2] Zhang Jie. Research on the protection and utilization of cultural heritage in Changzhou section of the Grand Canal [J]. Journal of Huaiyin Teachers College (Social Sciences Edition), 2014, 36(2): 215-221. (in Chinese)

[3] Qiao Guoqiang. Research on narratology: Proceedings of the Second National Symposium on Narratology and the Inaugural Conference of the Narratology Branch of the Chinese Society of Chinese and Foreign Literature and Art Theory [M]. Wuhan: Wuhan Publishing House, 2006: 284. (in Chinese) 
[4] (Australia) Sigmund Freud. Totem and Taboo [M]. The Culture of Wenliang. Beijing: Central Compilation \& Translation Press, 2005:114. (in Chinese)

[5] Yu Zhihong. Communication Semiotics [M]. Shanghai: Shanghai Jiaotong University Press, 2007: 21. (in Chinese)

[6] Zhang Min, Liu Lin, Xiong Zhiyong. Application of Scenario-based Methods in Product Design of Cultural Image $[\mathrm{J}]$. Packaging Engineering, 2016 (22): 164-168. (in Chinese) 